\title{
Commentary
}

See article on page 726

\section{Helicobacter pylori, ammonia and the brain}

Across the world, the human upper gastrointestinal tract is commonly infected with Helicobacter pylori. This urea splitting bacterium is now considered to be a causal agent in a spectrum of human disease, ranging from a limited antral gastritis to frank duodenal ulceration, in addition to an association with gastric carcinoma and MALT (mucosa associated lymphoid tissue) lymphoma. However, it is the presence of the bacterial urease which has stimulated recent interest into whether $H$ pylori contributes to the hyperammonaemia frequently observed in patients with chronic liver disease. If infection with this organism that produces ammonia was significantly to effect the circulating blood ammonia concentrations, then it was hypothesised that eradication treatment would improve hepatic encephalopathy. ${ }^{1}$

Chronic hepatic encephalopathy is a neuropsychiatric disorder with protean manifestations, the pathogenesis of which is poorly understood. ${ }^{2}$ It is generally underdiagnosed because, in most patients, the condition is subclinical. ${ }^{3}$ Psychometry and electroencephalography (EEG) have been the mainstay of objective diagnosis, but new techniques with diagnostic potential, such as magnetic resonance spectroscopy, are now becoming available. ${ }^{34}$

Raised systemic ammonia concentrations as a consequence of impaired hepatic ureagenesis or because of shunting of ammonia rich portal blood away from the liver have long been causally implicated in the development of hepatic encephalopathy. ${ }^{5}$ However, in each patient, the disorder probably has many contributing factors with increases in circulating gut derived toxins, including ammonia, and disturbances in cerebral neurotransmitters considered to be important. ${ }^{2}$ Nevertheless, blood ammonia concentrations are not always raised in patients with hepatic encephalopathy and ammonia concentrations do not necessarily correlate with patient symptoms or with the underlying neuropsychiatric status. ${ }^{6}$

The initial study implicating $H$ pylori as a risk factor for hepatic encephalopathy was published in $1993 .^{7}$ In a multicentre study of 273 patients with alcoholic hepatitis, $79 \%$ of those with hepatic encephalopathy had positive serology for $\mathrm{H}$ pylori, compared with $62 \%$ of those without overt encephalopathy. However, this study did not involve any endoscopic or breath test confirmation and can be criticised, because the use of serology alone did not distinguish between patients with an active infection or those with a previously eradicated infection. Most of the study patients who were not considered to be encephalopathic also had a high prevalence of $H$ pylori seropositivity in common with the population at large. It is, therefore, difficult to concur with the authors' ascertation that $H$ pylori was a significant risk factor for the development of hepatic encephalopathy.

The initial letter to the Lancet by Ito and colleagues on two patients with chronic liver disease who had received
$H$ pylori eradication treatment reported a subsequent reduction in circulating ammonia concentrations. ${ }^{8}$ However, further correspondence cast doubt on the suggestion that infection with the organism might contribute to encephalopathy. A Dutch group also reported a reduction in blood ammonia concentrations after treating $H$ pylori in 10 patients with chronic liver disease, but hyperammonaemia returned after a couple of months. ${ }^{9}$ A study from Edinburgh found that the presence of $H$ pylori made no difference to blood ammonia concentrations measured up to two hours after a urea load was given orally to 20 such patients. ${ }^{10}$ Both the latter two research groups concluded that any effect that eradication of $H$ pylori had on hyperammonaemia was probably as a result of antibiotic treatment on gut bacterial flora.

The issue is complicated because ammonia absorption is often unpredictable in liver disease, whereas that which might be attributed to $H$ pylori could be influenced by such factors as the nature of any gastric pathology present, the distribution and extent of bacterial colonisation in the stomach, and the presence of a collateral circulation. Careful studies looking at the relation between $H$ pylori as an ammonia producing organism and its possible effects on patients with chronic liver disease are required. The report by Miyaji and colleagues in this issue is therefore timely (see page 726 ). These investigators have tried to tackle some of the criticisms of the other groups in their study design. They looked at 50 patients with chronic liver disease of varying functional severity, but of undisclosed aetiology; not all patients underwent liver biopsy to confirm cirrhosis. It is not documented whether patients were abstinent from alcohol, as this may be a confounding factor when assessing hepatic encephalopathy. However, none had received $H$ pylori eradication treatment previously. In order to minimise any effects that triple therapy for $H$ pylori infection might have on other gut flora, all subjects received a regimen designed to reduce the colonic bacterial load for the two weeks prior to investigation. It should be noted that 32 patients subsequently had normal blood ammonia concentrations. This group contained 12 subjects who were $H$ pylori positive in two or more of the tests for the presence of the organism, including the instillation of phenol red dye into the stomach at endoscopy. This latter test allowed the subdivision of patients who were judged to have a limited or more generalised infection from the staining pattern produced. However, only those 18 patients who remained hyperammonaemic were selected for further study. Two thirds were infected with the organism, but all received triple therapy, which was found to be effective at repeat endoscopy four weeks later. Only the six patients with a generalised staining pattern had a significantly reduced blood ammonia concentration after eradication, which was maintained at three months. The authors therefore 
conclude that the extent of $H$ pylori colonisation affects blood ammonia concentrations in these patients.

Several criticisms can be made of this study. Reduction in gastric ammonia concentrations after triple therapy simply reflects eradication of $H$ pylori and no extrapolation can be made from this to blood ammonia concentrations. Furthermore, it would have been interesting to have documented the natural history of the 32 patients who developed normal circulating ammonia concentrations after the anti-encephalopathy regimen. We were not told whether blood ammonia returned to pretreatment concentrations. Did the subset of 12 patients who were $H$ pylori positive behave any differently to the others? It is therefore still not clear whether eradication therapy for $H$ pylori really does have an effect on hyperammonaemia, distinct from the effects of altering colonic bacterial flora by administration of antibiotics. Another major criticism is that no attempt was made to correlate ammonia concentrations either with the presence of a collateral circulation or with neuropsychiatric status.

Although hyperammonaemia is probably one of the most important causal factors in the development of hepatic encephalopathy, not all patients have high blood concentrations, whereas others may do so without any demonstrable ill effect. Future studies relating $H$ pylor infection to the hyperammonaemia of chronic liver disease should also document the clinical, neuropsychometric and EEG response of patients with hepatic encephalopathy to therapeutic interventions to clear the organism.
SIMON D TAYLOR-ROBINSON

Royal Postgraduate Medical School, Hammersmith Hospital and

Imperial College School of Medicine at St Mary's, London

Charing Cross Hospital, London

NEIL JACKSON

Royal Postgraduate Medical School,

CAMILLA BUCKLEY

Hammersmith Hospital, London

Correspondence to: Dr Simon Taylor-Robinson, Gastroenterology Unit, Hammersmith Hospital, Du Cane Rd, London W12 0HS

1 LeVeen HH, LeVeen EG, LeVeen RF. Awakenings to the pathogenicity of urease and the requirement for continuous long term therapy. Biomed Pharmacother 1994; 48: 157-66.

2 Jalan R, Seery J, Taylor-Robinson SD. Pathogenesis and treatment of hepatic encephalopathy. Aliment Pharmacol Ther 1996; 10: 681-97.

3 Conn HO. Assessment of the severity of hepatic encephalopathy. In: Rodes J, Arroyo V, eds. Therapy in liver diseases. Barcelona: Ediciones Doyma, 1992: 277-91

4 Seery JP, Taylor-Robinson SD. The application of magnetic resonance spectroscopy to the study of hepatic encephalopathy. $\mathcal{F}$ Hepatol 1996; 25: 988-98.

5 Hahn M. Die eck'sche fistel zwischen der unteren hohlvene und der pfortader und ihre folgen fur den organsimus. Arch Exp Pathol Pharmakol 1893; 32: 161 .

6 Stahl J. Studies of the blood ammonia in liver disease. Its diagnostic, prognostic and therapeutic significance. Ann Intern Med 1963; 58: 1-24.

7 Gubbins GP, Moritz TE, Marsano LS, Talwalkar R, McClain CJ, Mendenhall CL. Helicobacter pylori is a risk factor for hepatic encephalopathy: the ammonia hypothesis revisited. Am $f$ Gastroenterol encephalopathy: the

8 Ito S, Miyaji H, Azuma T, Li Y, Kato T, Kohli Y, Kuriyama M. Hyperammonaemia and Helicobacter pylori. Lancet 1995; 346: 124-5.

9 Quero JC, Hartmann IJ, de Rooij F, Wilson JH, Schalm SW. Hyperammonaemia and Helicobacter pylori. Lancet 1995; 346: 713-4.

10 Plevris NN, Morgenstern R, Hayes PC, Bouchier IA. Hyperammonaemia in cirrhosis and Helicobacter pylori infection. Lancet 1995; 346: 1104 